\title{
Schistosoma haematobium infections among schoolchildren in central Sudan one year after treatment with praziquantel
}

\author{
Abedaziz M Ahmed ${ }^{1}$, Hana Abbas', Fathi A Mansour ${ }^{1,2}$, Gasim I Gasim³ and Ishag Adam ${ }^{4}$
}

\begin{abstract}
Background: Chemotherapy with praziquantel (PZQ) is the mainstay of schistosomiasis control. However, there are recent concerns about tolerance or resistance to $\mathrm{PZQ}$, so that monitoring its efficacy in different settings is required.

Methods: A longitudinal study was conducted to evaluate the impact of PZQ for the treatment of Schistosoma haematobium infection among schoolchildren at Al Salamania, Central Sudan. Parasitological examinations for $S$. haematobium were performed in a cohort of schoolchildren (6-15 years of age) before and 1 year after treatment with a single dose of PZQ $40 \mathrm{mg} / \mathrm{kg}$.

Results: Out of 562 (309 boys and 253 girls) schoolchildren recruited from three elementary schools, 420 completed one longitudinal dataset that comprised of data from two time points; baseline, and follow-up 1 year after treatment with a single dose of PZQ $40 \mathrm{mg} / \mathrm{kg}$ for S. haematobium infection. A single dose of PZQ significantly reduced the prevalence of S. haematobium infection by $83.3 \%$ (from $51.4 \%$ to $8.6 \%$ ) and the geometric mean intensity of infection of positive individuals by $17.0 \%$ (from 87.7 to 72.8 eggs/10 ml of urine) 1 year after treatment. While there was no significant difference in the reduction of the prevalence of $S$. haematobium infection between the gender or age groups, there was a significantly higher reduction of intensity of S. haematobium infection among girls in comparison with boys.
\end{abstract}

Conclusion: There was a significant reduction of S. haematobium infection 1 year after PZQ treatment in this setting.

\section{Background}

Schistosomiasis is endemic in 74 countries [1], with a bulk of the global cases (90\%) residing in sub-Saharan Africa [1,2]. In 2007, the World Health Organization estimated 235 million cases of schistosomiasis worldwide, with 732 million people at risk of infection in known transmission areas [3]. In 2000, it was estimated that 70 million people had hematuria, 32 million had dysuria associated with Schistosoma haematobium, 18 million had major bladder wall pathology, 10 million people had S. haematobium related renal failure; and schistosomiasis related bladder cancer, resulting in an estimated mortality of 150000 people per year in subSaharan Africa [4]. In Sudan the risk for S. haematobium

\footnotetext{
* Correspondence: ishagadam@hotmail.com

${ }^{4}$ Faculty of Medicine, University of Khartoum, P.O. Box 102, Khartoum, Sudan Full list of author information is available at the end of the article
}

is widespread in the different regions [5-7] and school age children were at a higher risk of $S$. haematobium infection than the other age groups [6]. Due to many factors such as higher rates of water activities, anatomical vasculature supplying genitourinary structures and immunological factors, school-aged children are the group at highest risk of contracting S. haematobium infection [8-10].

Praziquantel (PZQ) is the mainstay of the current strategy against schistosomiasis morbidity control $[2,11]$. World Health Organization (WHO) guidelines recommend that in communities with schistosomiasis, and a prevalence of $10 \%$ up to $50 \%$, school-aged children and high-risk groups of adults should be treated with PZQ once every two years. In communities where prevalence is $50 \%$ and above, the same groups should be treated once a year [12]. Therefore mass therapy with PZQ has been employed in many national control programmes

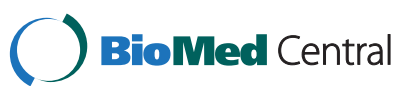


for schistosomiasis across sub-Saharan Africa, including Sudan. Schools were the target for this policy and treatment because of increased benefits of reducing infection burdens in children compared to adults and the ease of providing treatment $[13,14]$. The assessment of using annual PZQ treatment for schoolchildren is highly needed for both caregivers and health planners. The present longitudinal study aimed to investigate the prevalence and intensity of $S$. haematobium infection 1 year after treatment with PZQ among schoolchildren at Al Salamania in central Sudan so as to add to the body of research on the epidemiology and effects of schistosomiasis infections among schoolchildren in Sudan $[7,15,16]$.

\section{Methods}

The details of the method have been mentioned in the previous work on Schistosoma mansoni infection [16]. In summary, this was a continuation of the collaborative projects between the University of Khartoum and the Ministry of Health in Sudan, and it was part of a pilot program for schistosomiasis (both mansoni and haematobium) control that aimed at treating schoolchildren for schistosomal infections. A longitudinal study was conducted at $\mathrm{Al}$ Salamania, (Figure 1) which is an agricultural area in central Sudan, during the period October 2008 to November 2009. The study was conducted in three primary schools (for boys and girls in levels from level 1 up to level 8 , age between 1-16 years). All the children in these three schools were included in this study. Those students who received PZQ in the past 6 months were excluded from this study. After obtaining permission from the Education and Health Vice Chancellor and village head (sheikh) of this area, the study procedure was explained to the school authorities and parents/guardians of children. A longitudinal dataset that comprises data from two time points; baseline, and follow-up after 1 year was carried-out to determine the prevalence and intensity of urinary schistosomiasis among these schoolchildren. Students were provided with labeled $500 \mathrm{ml}$ specimen containers and asked to provide a urine sample between 10.00 and $13.00 / \mathrm{h}$. From each suspended sample, $10 \mathrm{ml}$ were filtered using a $25-\mathrm{mm}$ diameter filter holder and a Nucleopore ${ }^{\circledR}$ filter with a $12-\mu \mathrm{m}$ pore size as previously described [17]. The filters were placed on a glass slide and examined quantitatively

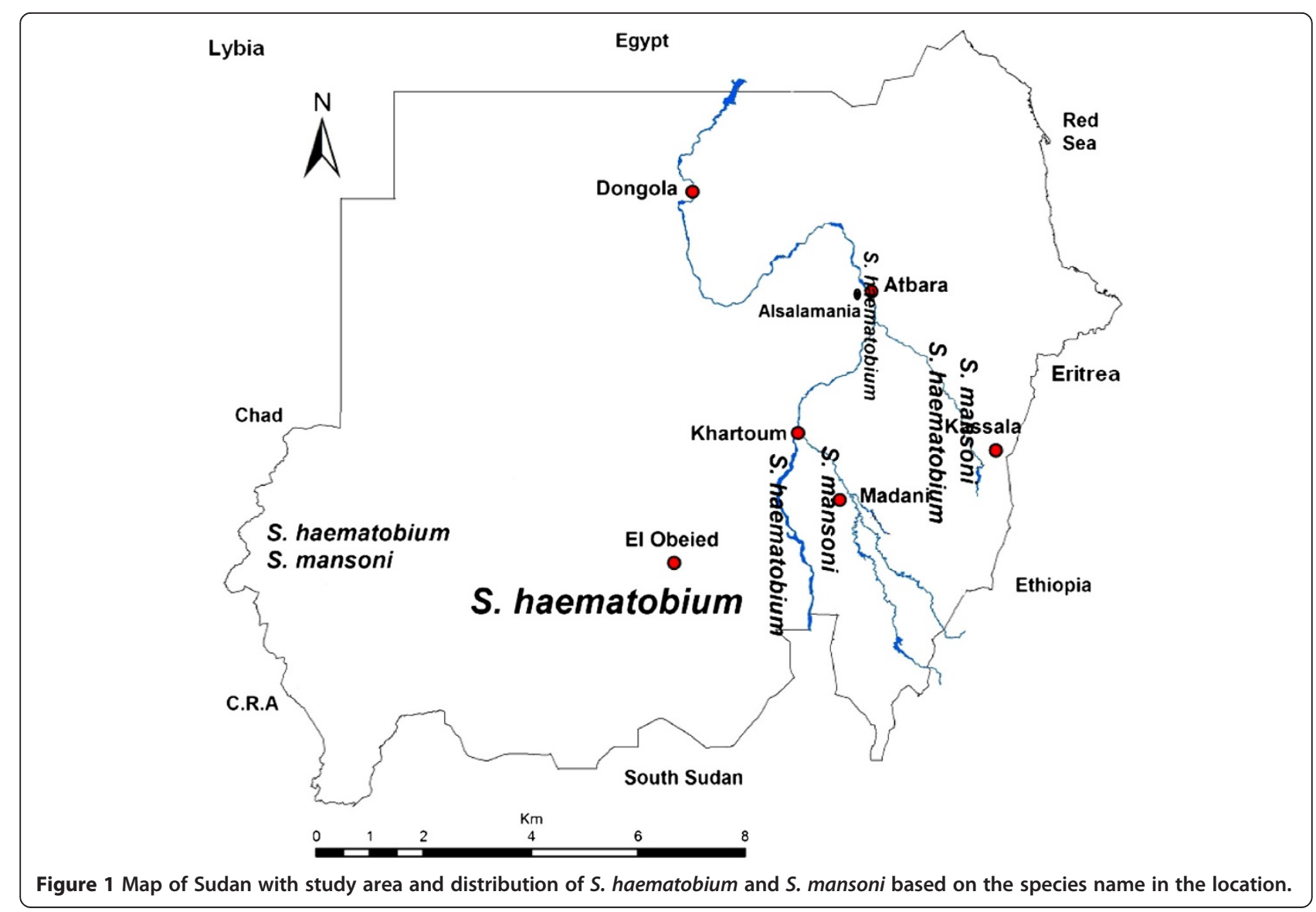


for S. haematobium eggs. Intensity of infection was expressed as eggs/10 $\mathrm{ml}$ of urine. Infection intensities were classified into two categories: (1) light infections ( $<50$ eggs/10 $\mathrm{ml}$ of urine) and (2) heavy infections ( $\geq 50$ eggs $/ 10 \mathrm{ml}$ of urine). For reducing the impact of zero egg count and normalization of the data the geometric mean of egg output was calculated in infected children only.

In the first survey, stool samples were examined for $S$. mansoni eggs and other helminths using the modified Kato technique for a single stool sample.

\section{Treatment}

Treatment was given not only to the children in the three schools that were involved in the surveys, but to the entire children in all elementary schools in the whole district (18 schools). Treatment was carried out by health teams of trained nurses and medical officers as part of the treatment campaign. The study team assisted this health team with treatment and also recorded and observed the treatment of the study schoolchildren. All schoolchildren were treated for schistosome infection with a single dose of $40 \mathrm{mg} / \mathrm{kg} \mathrm{PZQ}$, without considering the infection status, $600 \mathrm{mg}$ PZQ tablets, which can be subdivided into four segments of $150 \mathrm{mg}$ were used. The health team provided a dosing sheet that showed the correct dosage for different body weights. Children infected with other helminthes received albendazole orally.

\section{Data analysis}

Data were entered into the computer using SPSS for windows version 16.0 (SPSS Inc., Chicago, Illinois, USA) and double checked before analysis. The chisquare test was used to compare the differences in the prevalence (proportions) of infection. Student t-test was used to compare differences in the intensity of infection (eggs $/ 10 \mathrm{ml}$ of urine). A value of $\mathrm{P}<0.05$ was regarded as significant. Reduction in the prevalence and intensity (egg count in eggs/10 $\mathrm{ml}$ of urine) was calculated using the formulae below [18].

\section{Ethics}

The study received ethical clearance from the Research Board of Communicable Disease, Ministry of Health,
Sudan. The trial was registered under ClinicalTrials.gov NCT01558336

\section{Results}

Of 562 (309 boys and 253 girls) schoolchildren enrolled at baseline from the three schools, 420 were successfully traced and re-examined at baseline and followed up with two survey results for longitudinal parasitological data on S. haematobium. There was no significant difference in the data of children who dropped-out or missed the follow-up survey to those included in both surveys (data not shown). The mean age of these 562 children was 9.7 years (range, 6-15 years). Because few cases of $S$. mansoni (2.3\%), Hymenolepis nana (1.5\%), hookworm (1.1\%), Trichuris trichiura (1.1\%), and Ascaris lumbricoides $(0.01 \%)$ were detected in the first survey, stool examination was not conducted in the second survey.

Table 1 summarizes the parasitological results of $S$. haematobium infection in the children from three schools examined at baseline and 1 year after treatment. The prevalence of $S$. haematobium infection ranged from 38.5 to $59.21 \%$ with an overall prevalence of $51.4 \%$, egg counts ranged from 71.7 to 104.4 eggs $/ 10 \mathrm{ml}$ of urine with a mean of $87.7 \mathrm{eggs} / 10 \mathrm{ml}$ of urine among all children.

While there was no significant difference in prevalence of infection between boys and girls $(P=0.228)$, boys had significantly higher intensity of $S$. haematobium infection than girls $(\mathrm{P}<0.001$, Table 2$)$. Children of $<10$ years of age had a significantly higher rate of prevalence $(\mathrm{P}=0.001)$ and intensity of $S$. haematobium infection ( $\mathrm{P}$ $<0$.001) than those children $\geq 10$ years of age, (Table 3 )

A single dose of PZQ significantly reduced the prevalence of S. haematobium infection by $83.3 \%$ (from $51.4 \%$ to $8.6 \%$ ) and the intensity of infection by $17.0 \%$ (from 87.7 to 72.8 eggs $/ 10 \mathrm{ml}$ of urine) 1 year after treatment. While there was no significant difference in the reduction of the prevalence of S. haematobium infection between genders $(P=0.967)$ or age groups $(P=0.096)$, there was a significantly higher reduction of intensity of S. haematobium infection among girls in comparison with boys ( $P=0.001$, Table 2 and Table 3$)$. There was no significant difference in the reduction of intensity among different age groups. Interestingly, the reduction in prevalence was not significantly different in children with heavy or light infections Table 4.

Prevalence reduction $=(\%$ prevalence before treatment $-\%$ prevalence 1 year after treatment $)$
$/(\%$ prevalence before treatment $) \times 100 \%$.
Reduction in the intensity $=($ mean eggs $/ 10 \mathrm{ml}$ of urine before treatment

- mean eggs $/ 10 \mathrm{ml}$ of urine 1 year after treatment)

$/($ mean eggs $/ 10 \mathrm{ml}$ of urine before treatment $) \times 100 \%$. 
Table 1 The prevalence and intensity of S. haematobium infections in children from three schools in Al Salamania in Central Sudan

\begin{tabular}{|c|c|c|c|c|c|c|}
\hline \multicolumn{4}{|c|}{ Base line } & \multicolumn{3}{|c|}{ One year post-treatment } \\
\hline School & Children Examined & Prevalence & Intensity & Children Examined & Prevalence & Intensity \\
\hline & $n(\%)$ & $\%(95 \% \mathrm{Cl})$ & $(95 \% \mathrm{Cl})$ & $n(\%)$ & $\%(95 \% \mathrm{Cl})$ & $\overline{(95 \% \mathrm{Cl})}$ \\
\hline \multirow[t]{2}{*}{ AbHaraz } & $157(27.9)$ & 59.2 & 86.9 & $153(36.4)$ & 13.1 & 73.3 \\
\hline & & $51.4-66.7$ & $86.0-87.8$ & & $8.4-19.1$ & $71.6-74.5$ \\
\hline \multirow[t]{2}{*}{ Karni } & $223(39.7)$ & 56.5 & 104.4 & $147(35.0)$ & 9.5 & 87.7 \\
\hline & & $50.0-62.0$ & $103.4-105.4$ & & $5.5-15.1$ & 84.7-90.7 \\
\hline \multirow[t]{2}{*}{ El Dhiaga } & $182(32.4)$ & 38.5 & 71.7 & $(28.6) 20$ & 1.7 & 57.5 \\
\hline & & $31.6-45.7$ & $71.0-72.5$ & 1 & $0.3-5.3$ & $21.5-93.4$ \\
\hline \multirow[t]{2}{*}{ Total } & $562(100)$ & 51.4 & 87.7 & $420(100)$ & 8.6 & 72.8 \\
\hline & & $47.3-55.5$ & $87.3-88.1$ & & $6.2-11.5$ & $71.5-74.1$ \\
\hline $\mathrm{P}^{*}$ & & 0.001 & $<0.001$ & & 0.042 & $<0.001$ \\
\hline
\end{tabular}

*P values indicate the difference between the schools.

\section{Discussion}

The main findings of the current study are; high prevalence and intensity of S. haematobium among these children, especially boys and among those less than ten years of age, a significant reduction in prevalence $[83.3 \%$ (from $51.4 \%$ to $8.6 \%$ )] and intensity of S. haematobium infection [17.0\% (from 87.7 to $72.8 \mathrm{eggs} / 10 \mathrm{ml}$ of urine)] 1 year after PZQ treatment. While there was no significant difference in reduction of prevalence of S. haematobium infection between gender, age groups or level of infection, there was a significantly higher reduction of intensity of S. haematobium infection among girls in comparison to boys. The prevalence and intensity of infection of S. haematobium in this setting indicates that according to WHO criteria, regular treatment of schoolchildren in the area is indeed necessary [12].

The different age patterns for prevalence of infection of $S$. haematobium and differences in infection intensity observed in boys might indicate different water contact patterns.
Recently, Touré et al., [19] observed that a single round of PZQ treatment significantly reduced prevalence of S. haematobium infection by $87 \%$ (from $59.6 \%$ to $7.7 \%$ ) and intensity of infection by $92.8 \%$ (from 94.2 to $6.8 \mathrm{eggs} / 10 \mathrm{ml}$ of urine) two years post-treatment. Moreover, the proportion of school-age children with heavy $S$. haematobium infection decreased significantly (from 25\% before treatment to around 2-3\%) two years post-treatment. In Mozambique, two cohorts of $S$. haematobium infected schoolchildren were followed up two months after PZQ treatment. The prevalence of infection decreased from $54.2 \%$ and $51.7 \%$ in high and low transmission seasons to $30.3 \%$ and $1.8 \%$, respectively. The intensity of infection decreased from 23.3 eggs/ $10 \mathrm{ml}$ of urine at baseline to $15.6 \mathrm{eggs} / 10 \mathrm{ml}$ of urine in children treated during high transmission season, and from 23.5 eggs $/ 10 \mathrm{ml}$ urine to $7.3 \mathrm{eggs} / 10 \mathrm{ml}$ of urine children treated during low transmission season [20]. In Niger, three years after a single PZQ treatment, prevalence and intensity of $S$. haematobium infection

Table 2 The prevalence, intensity and reduction of S. haematobium infections in children from three schools in Al Salamania in Central Sudan at baseline and 1 year post treatment, relative to gender

\begin{tabular}{|c|c|c|c|c|}
\hline Variable & Total & Boys & Girls & $\mathbf{P}$ \\
\hline \multicolumn{5}{|l|}{ Base line } \\
\hline Children examined, $n(\%)$ & $562(100)$ & $309(55.0)$ & $253(45.0)$ & \\
\hline Prevalence,\% (95\% Cl) & $51.4(47.3-55.5)$ & $53.7(48.1-59.2)$ & $48.6(42.5-45.8)$ & 0.228 \\
\hline Intensity, (95\% Cl) & $87.7(87.2-88.1)$ & 101.4(100.6-102.1) & $74.0(72.2-74.8)$ & $<0.001$ \\
\hline \multicolumn{5}{|l|}{ One year post treatment } \\
\hline Children examined, $n(\%)$ & $420(100)$ & $237(56.4)$ & $183(43.6)$ & \\
\hline Prevalence,\% (95\% Cl) & $8.6(6.2-11.5)$ & $8.9(5.7-13.0)$ & $8.2(4.8-12.8)$ & 0.809 \\
\hline Intensity, (95\% Cl) & $72.8(71.5-74.1)$ & 99.5(97.7-101.3) & $46.2(44.3-48.1)$ & $<0.001$ \\
\hline Reduction in the prevalence,\% $(95 \% \mathrm{Cl})$ & $83.3(73.0-89.7)$ & 83.4(73.4-89.7) & $83.1(73.5-90.3)$ & 0.967 \\
\hline Reduction in the intensity, $(95 \% \mathrm{Cl})$ & $17.0(10.8-24.0)$ & $1.9(0.6-3.5)$ & $37.6(28.0-47.1)$ & 0.001 \\
\hline
\end{tabular}


Table 3 The prevalence, intensity and reduction of S. haematobium infections in children from three schools in Al Salamania in Central Sudan at baseline and 1 year post treatment, relative to age

\begin{tabular}{|c|c|c|c|c|}
\hline Variable & Total & Age $<10$ years & Age $\geq 10$ years & $\mathbf{P}$ \\
\hline \multicolumn{5}{|l|}{ Base line } \\
\hline Children examined, $n$ (\%) & $562(100)$ & $275(49.0)$ & $287(51.0)$ & \\
\hline Prevalence,\% (95\% Cl) & $51.4(47.3-55.5)$ & $58.2(52.2-64.0)$ & $44.9(39.3-50.7)$ & 0.001 \\
\hline Intensity, (95\% Cl) & $87.7(87.2-88.1)$ & $92.5(91.8-93.1)$ & $82.8(82.1-83.4)$ & $<0.001$ \\
\hline \multicolumn{5}{|l|}{ One year post treatment } \\
\hline Children examined, $n$ (\%) & $420(100)$ & $205(49.0)$ & $215(51.0)$ & \\
\hline Prevalence,\% (95\% Cl) & $8.6(6.2-11.5)$ & $9.8(6.2-4.4)$ & 7.4(4.4-11.6) & 0.397 \\
\hline Intensity, (95\% Cl) & $72.8(71.5-74.1)$ & $74.4(72.6-76.2)$ & $71.2(69.3-73.1)$ & 0.014 \\
\hline Reduction in the prevalence,\% $(95 \% \mathrm{Cl})$ & $83.3(73.0-89.7)$ & 83.3(74.3-90.0) & 83.5(73.4-90.6) & 0.096 \\
\hline Reduction in the intensity, $(95 \% \mathrm{Cl})$ & $17.0(10.8-24.0)$ & $19.6(13.7-27.8)$ & $14.0(8.6-21.1)$ & 0.327 \\
\hline
\end{tabular}

remained significantly lower than at baseline [21]. It is worth mentioning that different measures of intensity (arithmetic mean of all positive and negative individuals) were used in the other setting [22]; therefore the results are not directly comparable with this study. Previous reports from Khartoum, Sudan showed that PZQ treatment of schoolchildren infected with $S$. haematobium and/or S. mansoni was highly effective in terms of cure rate $(58 \%)$ and reduction (98\%) in egg count six weeks after the treatment [5].

We have recently shown that a single dose of PZQ reduced the overall prevalence of $S$. mansoni infection by $36.7 \%$ (from 59.1 to $37.4 \%$ ) and the intensity of infection by $41.1 \%$ (from 116.7 to 68.7 eggs per gram of stool) 1 year after treatment. The reduction in prevalence was significantly higher among the group of children with heavy infections (by $76.1 \%$, from 6.7 to $1.6 \%$ ) and among girls (by $54.1 \%, 42.3$ to $19.4 \%$ ) at 1 year after treatment [16]. Because infections with S. haematobium are more prevalent and generally more pathogenic in sub-Saharan Africa [4], perhaps more PZQ should be used against $S$. haematobium rather than S. mansoni, [4]. Evidence suggests that $S$. haematobium is more sensitive to PZQ than $S$. mansoni [23]. Yet, there are some reports of $S$. haematobium infections that failed to respond to PZQ $[24,25]$.
In the current study, there was no significant difference in reduction of prevalence of S. haematobium infection between the levels of infection. Recent reports showed that children lightly infected with S. haematobium had a better cure rate than heavily infected children [20]. Previously, Utzinger et al. and Raso et al. $[26,27]$ found an inverse relationship between cure rate and intensity of infection in intestinal schistosomiasis. A recent systematic review and meta-analysis showed that praziquantel is an effective agent in schistosomiasis treatment, and multiple doses might improve its efficacy [28].

In schistosomiasis, infection intensity is a better indicator of morbidity than prevalence as it reflects the number of worms infecting the individual and it is also a more reliable marker of treatment success defined as the removal of egg-laying worms, which is usually the case in treatment programs and larger epidemiological studies $[18,29,30]$. One of the limitations of the current study is the use of single egg counts. A single egg count is a less reliable tool for estimating prevalence and infection status of schistosomiasis. The examination of two or more specimens per child would have led to even higher estimates of total prevalence and intensity. The other limitation of the current work is lack of information on seasonality of the transmission of $S$. haematobium

Table 4 Reduction in the prevalence of S. haematobium infections in children from three schools in Al Salamania in Central Sudan, relative to the level of infections

\begin{tabular}{lllll}
\hline Variable & Total & Light infection & Heavy infection & Negative \\
\hline Base line & & & & \\
\hline Children examined, $n(\%)$ & $562(100)$ & $137(24.4)$ & $152(27.0)$ & $273(48.6)$ \\
\hline Prevalence, $\%(95 \% \mathrm{Cl})$ & $51.4(47.3-55.5)$ & $24.4(21.0-28.0)$ & $27.0(23.5-30.8)$ & - \\
\hline One year post treatment & & & \\
\hline Children examined, $n(\%)$ & $420(100)$ & $17(4.0)$ & $19(4.5)$ & $384(91.4)$ \\
\hline Prevalence, $\%(95 \% \mathrm{Cl})$ & $8.6(6.2-11.5)$ & $4.0(2.4-6.3)$ & $4.5(2.8-6.8)$ & - \\
\hline Reduction in the prevalence, $\%(95 \% \mathrm{Cl})$ & $83.3(73.0-89.7)$ & $82.0(63.1-93.7)$ & $83.3(70.8-91.4)$ & - \\
\hline
\end{tabular}


infection in the area, which might have influenced the response to PZQ treatment. Recent reports showed that adults and preschool children were at risk of schistosomiasis and can contribute to the transmission [31,32]; therefore schistosomiasis control interventions should also target these groups in addition to school children in endemic areas.

\section{Conclusion}

There was a significant reduction of S. haematobium infection 1 year after PZQ treatment in this setting.

\section{Competing interests}

The authors declare that they have no competing interests.

\section{Acknowledgements}

Authors are very grateful to the children who participated in the study and to all the staff of the schools. I. Adam was funded by University of Khartoum, Sudan

\section{Author details}

'Schistosomiasis Research Laboratory, Faculty of Science, University of Khartoum, Khartoum, Sudan. ${ }^{2}$ Department of Epidemiology, Tropical Medicine Research Institute, Khartoum, Sudan. ${ }^{3}$ Faculty of Medicine, Qassim University, Qassim, Kingdom of Saudi Arabia. ${ }^{4}$ Faculty of Medicine, University of Khartoum, P.O. Box 102, Khartoum, Sudan.

\section{Authors' contributions}

AAA and IA designed the study. HA, FAM and GIG carried out the study and participated in the statistical analysis and procedures. AAA and IA coordinated and participated in the design of the study, statistical analysis and the drafting of the manuscript. All the authors read and approved the final version.

Received: 19 March 2012 Accepted: 7 June 2012

Published: 7 June 2012

\section{References}

1. Steinmann P, Keiser J, Bos R, Tanner M, Utzinger J: Schistosomiasis and water resources development: systematic review, meta-analysis, and estimates of people at risk. Lancet Infect Dis 2006, 6:411-425.

2. WHO: Prevention and control of schistosomiasis and soil-transmitted helminthiasis: Report of a WHO expert committee. In WHO Technical Report Series No. 912. pp. 1-57. Geneva: World Health Organization; 2002.

3. WHO: Preventive Chemotherapy Data bank. 2009. available online at: http:// www.who.int/neglected_diseases/preventive_chemotherapy/databank/en/ index.html.

4. Van der Werf MJ, de Vlas SJ, Brooker S, Looman CW, Nagelkerke NJ, Habbema JD, Engels D: Quantification of clinical morbidity associated with schistosome infection in sub-Saharan Africa. Acta Trop 2003, 86:125-139.

5. Mohammed EH, Eltayeb M, Ibrahim H: Haematological and biochemical morbidity of Schistosoma haematobium in school children in Sudan. Sultan Qaboos Univ Med J 2006, 6:59-64.

6. Ahmed AA, Afifi AA, Adam I: High prevalence of Schistosoma haematobium infection in Gereida Camp, in southern Darfur, Sudan. Ann Trop Med Parasitol 2009, 103:741-743.

7. Deribe K, Eldaw A, Hadziabduli S, Kailie E, Omer MD, Mohammed AE, Jamshed T, Mohammed EA, Mergani A, Ali GA, Babikir K, Adem A, Hashim F: High prevalence of urinary schistosomiasis in two communities in South Darfur: implication for interventions. Parasit Vectors 2011, 4:14.

8. Bichler KH, Feil G, Zumbrägel A, Eipper E, Dyballa S: Schistosomiasis: a critical review. Curr Opin Urol 2001, 11:97-101.

9. Mutapi F, Burchmore R, Mduluza T, Midzi N, Turner CM, Maizels RM: Agerelated and infection intensity-related shifts in antibody recognition of defined protein antigens in a schistosome-exposed population. I Infect Dis 2008, 198:167-175.
10. Engels D, Chitsulo L, Montresor A, Savioli L: The global epidemiological situation of schistosomiasis and new approaches to control and research. Acta Trop 2002, 82:139-146.

11. WHO: Deworming for health and development. Report of the third global meeting.: WHO/CDS/CPE/PVC/2005.14.

12. WHO: Schistosomiasis and soil transmitted helminth infections - preliminary estimates of the number of children treated with albendazoleor mebendazole. http://www.who.int/wer No. 16, 2006, 81, 145-164.

13. Kabatereine NB, Brooker S, Koukounari A, Kazibwe F, Tukahebwa EM, Fleming FM, Zhang YB, Webster JP, Stothard JR, Fenwick A: Impact of a national Helminth control programme on infection and morbidity in Ugandan schoolchildren. Bull World Health Organ 2007, 85:91-99.

14. Zhang Y, Koukounari A, Kabatereine N, Fleming F, Kazibwe F, Tukahebwa E, Stothard JR, Webster JP, Fenwick A: Parasitological impact of 2-year preventive chemotherapy on schistosomiasis and soil-transmitted helminthiasis in Uganda. BMC Med 2007, 5:27.

15. Mahgoub HM, Mohamed AA, Magzoub M, Gasim Gl, Eldein WN, Ahmed AA, Adam I: Schistosoma mansoni infection as a predictor of severe anaemia in schoolchildren in eastern Sudan. J Helminthol 2010, 84:132-135.

16. Ahmed AM, El Tash LA, Mohamed EY, Adam I: High levels of Schistosoma mansoni infections among schoolchildren in central Sudan one year after treatment with praziquantel. J Helminthol 2012, 86:228-232.

17. Kahama Al, Odek AE, Kihara RW, Vennervald BJ, Kombe Y, Nkulila T, Hatz CF, Ouma JH, Deelder AM: Urine circulating soluble egg antigen in relation to egg counts, haematuria, and urinary tract pathology before and after treatment in children infected with Schistosoma haematobium in Kenya. AmJTrop Med Hyg 1999, 61:215-219.

18. Montresor A, Crompton DW, Bundy DAP, Hall A, Savioli L: Guidelines for the evaluation of soil-transmitted helminthiasis and schistosomiasis at community level. Geneva: World Health Organization; 1998:45.

19. Touré S, Zhang Y, Bosqué-Oliva E, Ky C, Ouedraogo A, Koukounari A, Gabrielli AF, Bertrand S, Webster JP, Fenwick A: Two-year impact of single praziquantel treatment on infection in the national control programme on schistosomiasis in Burkina Faso. Bull World Health Organ 2008, 86:780-787.

20. Augusto G, Magnussen P, Kristensen TK, Appleton CC, Vennervald BJ: The influence of transmission season on parasitological cure rates and intensity of infection after praziquantel treatment of Schistosoma haematobium-infected schoolchildren in Mozambique. Parasitology 2009 136:1771-1779.

21. Garba A, Campagne G, Tassie JM, Barkire A, Vera C, Sellin B, Chippaux JP: Long-term impact of a mass treatment by praziquantel on morbidity due to Schistosoma haematobium in two hyperendemic villages of Niger. Bull Soc Pathol Exot 2004, 97:7-11.

22. Utzinger J, Keiser J: Schistosomiasis and soil-transmitted helminthiasis: common drugs for treatment and control. Expert Opin Pharmacother 2004, 5:263-285

23. Botros S, Pica-Mattoccia L, William S, El-Lakkani N, Cioli D: Effect of Praziquantel on the immature stages of Schistosoma haematobium. Int J Parasitol 2005, 35:1453-1457.

24. Da Silva IM, Thiengo R, Conceicao MJ, Rey L, Lenzi HL, Filho EP, Ribeiro PC: Therapeutic failure of praziquantel in the treatment of Schistosoma haematobium infection in Brazilians returning from Africa. Memorias do Instituto Oswaldo Cruz 2005, 100:445-449.

25. Alonso D, Munoz J, Gascon J, Valls ME, Corachan M: Failure of standard treatment with praziquantel in two returned travelers with Schistosoma haematobium infection. AmJTrop Med Hyg 2006, 74:342-344.

26. Utzinger J, N'Goran EK, N'Dri A, Lengeler C, Tanner M: Efficacy of praziquantel against Schistosoma mansoni with particular consideration for intensity of infection. Trop Med Int Health 2000, 5:771-778.

27. Raso G, N'Goran EK, Toty A, Luginbühl A, Adjoua CA, Tian-Bi NT, Bogoch II, Vounatsou P, Tanner M, Utzinger J: Efficacy and side effects of praziquantel against Schistosoma mansoni in a community of western C'ote d'Ivoire. Trans R Soc Trop Med Hyg 2004, 98:18-27.

28. Liu R, Dong HF, Guo Y, Zhao QP, Jiang MS: Efficacy of praziquantel and artemisinin derivatives for the treatment and prevention of human schistosomiasis: a systematic review and meta-analysis. Parasit Vectors 2011, 4:201.

29. Jordan P, Webbe G: Epidemiology. In Human schistosomiasis. Edited by Jordan P, Webbe G, Sturrock RF. Wallingford, UK: CAB International; 1993:87-158. 
30. Davis A: Clinical trials in parasitic diseases. Trans R Soc Trop Med Hyg 2004, 98:139-141.

31. Njenga SM, Mwandawiro CS, Muniu E, Mwanje MT, Haji FM, Bockarie MJ: Adult population as potential reservoir of NTD infections in rural villages of Kwale district, Coastal Kenya: implications for preventive chemotherapy interventions policy. Parasit Vectors 2011, 4:175

32. Dabo A, Badawi HM, Bary B, Doumbo OK: Urinary schistosomiasis among preschool-aged children in Sahelian rural communities in Mali. Parasit Vectors 2011, 4:21.

doi:10.1186/1756-3305-5-108

Cite this article as: Ahmed et al: Schistosoma haematobium infections among schoolchildren in central Sudan one year after treatment with praziquantel. Parasites \& Vectors 2012 5:108

\section{Submit your next manuscript to BioMed Central and take full advantage of:}

- Convenient online submission

- Thorough peer review

- No space constraints or color figure charges

- Immediate publication on acceptance

- Inclusion in PubMed, CAS, Scopus and Google Scholar

- Research which is freely available for redistribution 